\title{
AEROMAGNETIC MAP OF THE WAUSAU AREA, WISCONSIN
}

By

John R. Henderson, Natalie S. Tyson, and James R. Page

GEOPHYSICAL INVESTIGATIONS

MAP GP-401

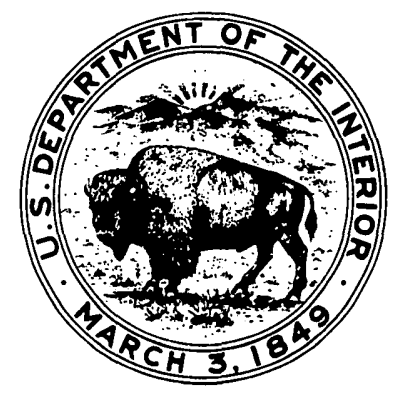

PUBLISHED BY THE U. S. GEOLOGICAL SURVEY 